Motivation in caring labor:

Implications for the well-being and employment outcomes of nurses 


\begin{abstract}
For nurses and other caregivers there is a strong emphasis on prosocial forms of motivation, or doing the job because you want to help others, even in formal, institutionalized care settings. This emphasis is based in gendered assumptions that altruistic motivations are the "right" reasons for being a nurse and lead to the best outcomes for workers and patients. Other motivations for pursuing care work, particularly extrinsic motivation, depart from the prosocial model of care and may be indicative of substandard outcomes, but little research has examined variation in care workers' motivations for doing their jobs. In this study, we use survey data collected from 730 acute care hospital nurses working within one health care system in the Midwestern United States to examine whether different sources of motivation for being a nurse are related to nurse job burnout, negative physical symptoms, and turnover intentions. Our findings suggest that nurses who have high intrinsic and extrinsic motivation actually have better perceived health and employment outcomes (i.e., less likely to say that they will leave, lower burnout, fewer negative physical symptoms) than those with high prosocial motivation, who are more likely to report job burnout.
\end{abstract}

Keyword: United States; nursing workforce; care work; job burnout; intent to turnover; prosocial motivation; intrinsic motivation; extrinsic motivation 
There is extensive research on nurses' job burnout, well-being, and retention (see literature reviews by Hayes et al. (2006), Lang, Ochsmann, Kraus, and Lang (2012), Larrabee, Janney, Ostrow, Withrow, Hobbs, and Burant (2003)), but few studies have empirically incorporated worker motivations for doing their job as predictors of worker outcomes. Extending Self-Determination Theory (SDT), which primarily focuses on the effect of intrinsic (i.e., because the work is fun or interesting) and extrinsic (i.e., because one gets money and other rewards) motivations for doing work (Ryan \& Deci, 2000), recent research by Adam Grant and others has highlighted the benefits of prosocial motivation in the workplace (Grant, 2008a; Grant, 2008b; Grant \& Berry, 2011; Grant \& Sonnentag 2010). Prosocial motivation focuses on performing the work because of a desire to maintain or enhance the well-being of others. Grant's research program suggests that having high prosocial motivation may be related to better outcomes at work, including improved worker persistence, performance, and productivity. Further, this desire to help others is often described as the "right" reason for performing a care work job like nursing (Heyes, 2005; Meagher, 2006; Nelson, 1999).

However, scholars of workers in care work occupations have long argued that high prosocial motivation may be at risk of identifying too closely with the job and less likely to develop a "healthy" distance from the interactional stresses of the work (Maslach, Schaufeli, \& Leiter, 2001; Hochschild, 1983; Erickson \& Ritter, 2001). Consequently, high prosocial motivations among nurses may be related to poorer worker outcomes, including higher burnout and reduced retention (Erickson \& Ritter, 2001). Further, literature on care work occupations has argued that the strong emphasis on prosocial motivation in nursing and other care work occupations - while other types of motivations such as extrinsic or intrinsic motivation are dismissed or even viewed as "wrong" - is heavily gendered (England, Budig, \& Folbre, 2002; 
Duffy, 2005). Indeed, the nurturing, altruistically motivated individual - typically female - plays strongly into our image of the ideal caretaker, someone who has an innate and maternal desire to care for others (Gerstel, 2000; Thistle, 2006). To date, however, there has been little consideration of how different motivations for performing the work are related to worker outcomes such as burnout and employment intentions within these types of gendered care work occupations.

In the current study, we aim to make two contributions. First, we clarify the relationship between three forms of motivation and worker outcomes, including job burnout, negative physical symptoms, and intent to turnover. We do so by examining the tensions between literatures examining care work occupations (Maslach et al., 2001; Hochschild, 1983; Erickson \& Ritter, 2001), the effects of prosocial motivation (Grant, 2008a, 2008b, 2013) and the impact of intrinsic and extrinsic motivation (e.g., Ryan \& Deci, 2000). Although the research on care work tends to pit prosocial motivation against extrinsic motivation, and SDT has tended to contrast intrinsic and extrinsic motivations, we extend both literatures by suggesting that nursing provides an occupational context where all three forms of motivation may be consequential for self-reported health and turnover intentions. Second, by examining these relationships within the context of nursing, we also address concerns raised about the gendered assumptions underlying motivations to perform caring labor and how these are related to how we conceptualize what constitutes good "care." As nursing and other health care occupations seek to recruit and retain a more diverse workforce, making such assumptions explicit, as well as examining the extent to which theoretical relationships hold within this highly gendered occupational context, has implications for how organizations might approach nursing recruitment and how best to support nurses' health and retention in the years to come. 


\section{Sources of Motivation}

Researchers have long recognized that motivation, or the reasons and desires that drive action, can derive from different sources (Herzberg, Mausner, \& Snyderman, 1959; Kalleberg, 1977). Furthermore, self-determination theory (SDT) and other motivational models suggest that the quality of motivation, that is the underlying reasons guiding one's behavior, can have important implications for individual well-being (Bono \& Judge, 2003; Deci \& Ryan, 2000;

Sheldon \& Elliot, 1998; Sheldon \& Elliott, 1999). As described above, in this study we are interested in three types: prosocial, intrinsic, and extrinsic motivation.

Research on why people choose a career that involves providing care in a formal context, such as nurses, typically focuses on whether individuals are motivated by "love or money" (England, Folbre, \& Leana, 2012; Folbre \& Nelson, 2000). In this work, "love" represents prosocial motivations such as the desire to maintain or enhance the well-being of others, while "money" focuses on the extrinsic rewards of a job, including wages, benefits, or an expected promotion or raise (Herzberg et al.,1959; Kalleberg, 2011; Grant, 2008b). Prosocial motivations are derived from the desire to protect and promote the welfare of others, which in the workplace, may mean that an individual performs a work task because it is a means to helping others (Batson \& Powell, 2003; Grant, 2008a). Literature on caring labor has discussed how both care workers and those they care for look to family relationships as a model for the motivations underlying entry into formal, paid caregiving (Meagher, 2006; Dodson \& Zincavage, 2007). Thus, even in formal, institutionalized care settings, there is a strong emphasis on prosocial motivation for doing one's job.

Prosocial motivation is often contrasted with extrinsic motivation, or motivation to perform work because of external job rewards, such as wages, benefits, or the opportunity for a 
promotion (Herzberg et al., 1959); in other words, "love" stands opposite of market exchange (Nelson, 1999). Wages for nurses rose substantially in the late 1990s as shortages created an increased demand for qualified workers (Buerhaus, Staiger \& Auerbach, 2009; Jacoby, 2006; U.S. Department of Labor, 2012). The combination of general economic instability over the last several decades with the decline in many middle-class occupations (Autor, 2010), suggests that the extrinsic rewards of nursing may now be a stronger motivation for a career in caring labor than in the past.

A further implication of focusing on the prosocial/extrinsic dichotomy in studying the motivations toward, and consequences of, performing caring labor is the tendency to overlook the role played by intrinsic motivation (e.g., Nesje, 2015). Intrinsic motivation is rooted in the nature of the work required by the job; that is, it relates to the enjoyment derived from performing the routine and required job tasks associated with a particular occupation. In the context of research on caring labor, some have conflated intrinsic and prosocial motivations. For example, England et al. (2012) write that “...there is little about the actual doing of care work that is in itself inherently interesting or pleasurable, independent of the prosocial aspects of the work such as helping others" (p.22). Accordingly, England and colleagues argue that individuals do not have intrinsic motivation to pursue caring labor, only prosocial motivation. However, there is evidence in the nursing literature that job qualities such as skill variety, autonomy and discretion at work, and opportunities to be creative are perceived to be enjoyable and have the potential to improve job quality independent of any social benefit to others (Janssen, De Jonge, \& Bakker, 1999; Houkes et al., 2003). Further, as many of the traditional "caring" tasks are now assigned to health care aides and assistants, the technical skill requirements for nurses have risen, 
particularly in some specialties and settings (Judd \& Sitzman, 2013). Such developments may also be seen by nurses as increasing the intrinsic rewards of the job.

\section{Gendered Assumptions about Care Motives}

The conflation of prosocial and intrinsic motivation in conceptualizing caring labor may stem from the gendering of such jobs. Because caring labor jobs are assumed to require altruism, compassion, and kindness - qualities that are thought to be embodied by women -the skills needed to perform these jobs are often overlooked (Duffy, 2005; England, Budig, \& Folbre, 2002; Cotter, Hermsen, \& Vanneman, 2004). As many scholars have argued, it is the conflation of "care" with "femaleness" that leads to the continued misunderstanding of caring labor jobs, as well as to the persistent stereotyping of such jobs as "feminine" and, in so doing, the rationale for their relatively lower pay than "masculine" jobs (Dodson \& Zincavage, 2007; England, 2005; England, Budig, \& Folbre, 2002; Gauchat, Kelly, \& Wallace, 2012).

Cultural expectations for individuals' motivations for pursuing a career in caring labor are also gendered and value-laden. Meagher (2006) rightly points out that care work has both a "moral/motivational" dimension as well as a technical/practical dimension: caregivers both care about and care for those they tend (p.35). However, while both dimensions of care are usually recognized as necessary, most theoretical accounts of good care stress the particular significance of prosocial motivations, or caring about patients (Attree, 2001; Basford \& Slevin, 2003; Himmelweit, 1999; Stone, 2000), and personal qualities such as altruism and kindness that, as argued above, are strongly associated with femaleness (Pullen \& Simpson, 2009).

In contrast, extrinsic motivations belong to the public sphere and marketplace, are viewed as standing in opposition to the familial ideal of performing care work, and therefore are viewed skeptically (Meagher, 2006; Nelson, 1999). For example, in an article titled "The Economics of 
Vocation or 'Why Is a Badly Paid Nurse a Good Nurse?,"” Heyes (2005) argues that a willingness to accept lower wages, all else equal, distinguishes a "good" nurse from the "wrong sort," or the sort that is highly motivated by extrinsic rewards. Based on this logic, raising nurses' pay would reduce the proportion of nurses who are motivated primarily by prosocial motivations or may even erode or "drive out" caring feelings by encouraging the pursuit of extrinsic rewards (Heyes, 2005).

Nelson points out that the belief that being interested in money signals "greediness" may be, in some cases, a strong gender or class bias. The image of the white, middle class female the "angel of the house" - who has no monetary concerns may be our ideal caregiver, but for most people, gaining access to money is a necessity (Nelson, 1999, p.49). Further, as Nelson and Folbre (2006) point out, just because someone is motivated by love or altruism does not necessarily mean that they have the technical skills necessary to be a competent nurse, nor does it mean that they are "good" at caring. Motivations and intentions do not necessarily translate into results just because a nurse may be female, yet nursing has long suffered from the stereotype that its practitioners need only be motivated by love and naturally altruistic virtues (Nelson \& Folbre, 1996). As mentioned above, these tendencies also lead intrinsic motivations - or inherent interests in the job tasks themselves - to be neglected in conversations about the consequences of different motives to perform caring labor.

\section{The Current Study}

In the current study, we examine how motivations influence care workers' experience of work, their well-being, and their commitment to their employer. We focus on three outcomes: job burnout, physical symptoms, and an individual's intent to leave his or her current employer. We outline our expectations for the different forms of motivation below. 
Job burnout. Burnout is a unique type of stress syndrome that is fundamentally characterized by "emotional exhaustion" (Cordes \& Dougherty, 1993; Maslach et al., 2001). Within nursing, the emotional demands of the work can exhaust a nurse's capacity to be involved with, and responsive to, the needs of patients (Barron \& West, 2007; Brotheridge \& Grandey, 2002). The emotional exhaustion that results from the personal and intimate needs of patients may prompt actions to distance one's self emotionally and cognitively from one's work, presumably as a way to cope with the work overload. Such emotional exhaustion may result from "identifying" too closely with one's patients, and some research has suggested that moderating one's compassion for clients by maintaining an emotional distance from them (i.e., detached concern) may be a way of protecting oneself from intense emotional arousal that could interfere with functioning effectively on the job (Maslach et al., 2001; Hochschild, 1983; Erickson \& Ritter, 2001).

Perceived physical well-being. Negative physical symptoms are unpleasant selfperceptions of one's physical self and have been associated with negative emotions and work strain (Gendolla et al., 2005; Lang et al., 2012; Pearlin, 1989). These unpleasant perceptions of one's health may or may not be grounded in actual physical problems and include experiences like dizziness, a rapid heartbeat, and cold hands. Research has linked physical symptoms to emotions, finding that negative affect and the presence of emotional requirements - such as those required of nurses - are positively related to the experience of physical symptoms (Schaubroeck \& Jones, 2000).

Intent to turnover. Intent to turnover from, or leave, one's current employer is an indicator of a worker's attachment to the organization, rather than to the profession of nursing, and is thus an aspect of her or his organizational commitment. Intention to turnover has been 
shown to be positively related to quitting one's job and is a reflection of job satisfaction and the ability of organizations to retain workers (Hayes et al., 2006; Larrabee et al., 2003).

Hypotheses. Substantial attention has recently been given to work by Grant (2008a, 2008b, 2013) on the benefits of prosocial motivation in workplace. Research by Grant and others suggests that high prosocial motivation at work can contribute to improved persistence, performance, and productivity, particularly when accompanied by high intrinsic motivation (Grant, 2008a; Grant, 2008b; Grant \& Sonnentag, 2010; Grant \& Berry, 2011). Thus, Grant suggests that high prosocial motivation would have positive influence on workers' experiences at work, physical well-being, and commitment to their employer, as high prosocial motivation increases workers' positive feelings at work.

However, literature on care work and emotional labor stands in contrast to the work of Grant in the context of human service occupations that value authentic and emotionally intense connections between human beings. Hochschild (1983) and others argue that workers with high prosocial motivation would be at risk of identifying too closely with the job and less likely to develop a "healthy" distance from the interactional stresses of the work (Maslach et al., 2001; Hochschild, 1983; Erickson \& Ritter, 2001). Consequently, nurses with high prosocial motivations may be more likely to experience burnout, negative physical symptoms, and potentially lower commitment to their employer (Erickson \& Ritter, 2001). In the current study, we follow the research of care work and emotional labor scholars and predict that high prosocial motivation will be related to high job burnout, higher negative physical symptoms, and higher intent to turnover.

Hypothesis 1a: Prosocial motivation will be positively related to burnout.

Hypothesis 2a: Prosocial motivation will be positively related to number of physical symptoms. 
Hypothesis 3a: Prosocial motivation will be positively related to intent to turnover.

While our predictions about the relationship between prosocial motivation and worker outcomes depart from the work of Grant, our predictions related to intrinsic motivation and worker outcomes are consistent with his work and SDT (Deci \& Ryan, 2000; Sheldon et al., 1998). According to self-determination theory, high intrinsic motivation - or being motivated by task enjoyment and interest - is associated with greater psychological need satisfaction (Ryan \& Deci, 2000; Janssen et al., 1999; Houkes et al., 2003), which is a prerequisite for individual wellbeing and thriving (Deci \& Ryan. 2000). While research on intrinsic motivation among nurses is limited, correlational results reported by Janssen et al. (1999) suggest that intrinsic motivation is negatively related to intent to turnover. Thus we predict that high intrinsic motivation will be negatively related to job burnout, negative physical symptoms, and intent to turnover. Hypothesis $1 \mathrm{~b}$ : Intrinsic motivation will be negatively related to burnout. Hypothesis $2 b$ : Intrinsic motivation will be negatively related to number of physical symptoms. Hypothesis $3 b$ : Intrinsic motivation will be negatively related to intent to turnover.

Finally, there has been little research examining the relationship between extrinsic motivation and burnout among human service workers, but in more general studies testing selfdetermination theory, extrinsic motivation has been found to be associated with poorer psychological need satisfaction and low well-being (Ryan \& Deci, 2000). Indeed pursing activities for extrinsic reasons has been shown to thwart psychological need satisfaction (Sheldon et al., 1998). Consequently, we expect that extrinsic motivation will be positively related to burnout and negative physical symptoms. Self-determination theory also predicts that high extrinsic motivation is positively associated with intent to turnover because the pursuit of extrinsic rewards can undermine an individual's commitment to their job and employer (Gagné 
\& Deci, 2005). However, past research on care workers' employment intentions shows that extrinsic rewards and promotion opportunities are strong negative predictors of their intentions to turnover, suggesting that extrinsic motivation also positively contributes to their levels of commitment (Tourangeau et al., 2010). Consequently, we depart from SDT and hypothesize that in our population of nurses, extrinsic motivation will be negatively related to intent to turnover. Hypothesis 1c: Extrinsic motivation will be positively related to burnout.

Hypothesis 2c: Extrinsic motivation will be positively related to number of physical symptoms. Hypothesis 3c: Extrinsic motivation will be negatively related to intent to turnover.

\section{Summary}

As argued above, the familial ideal of caregiving is the dominant model of conceptualizing care even in formal care settings, which consistently emphasize the importance of prosocial motivation. At the same time, the technical requirements to provide care as a nurse and extrinsic rewards (e.g., wages) have increased, which may encourage individuals who have intrinsic or extrinsic motivation to pursue caring labor. The aim of this study is to examine the relationships between source of motivation to pursue care work and a variety of worker outcomes, including job burnout, physical well-being, and intent to leave one's job. Put more broadly, we aim to understand whether source of motivation and care dimensions influence nurses' well-being and employment decisions. To address this aim, we draw on survey data from a sample of 730 nurses in a large and diverse health system in the United States.

\section{METHODS}

\section{Data and Sample}

To test the proposed relationships, we use survey data collected from RNs employed by a large, Midwestern hospital system that serves urban, suburban, and rural communities. These 
data are part of a larger project examining the effect of identity and emotion on the health and well-being of RNs. A complete listing of full-time, direct care RNs was obtained from the health system's human resources department and written questionnaires in sealed envelopes were distributed to eligible RNs employed within each hospital $(\mathrm{N}=1702)$. Completed surveys were returned by mail from 762 participants, or $44.8 \%$ of the original eligible sample. This response rate is consistent with other studies among registered nurses (e.g., Lucero, Lake, and Aiken 2010). Cases with missing observations were dropped from the analysis; this resulted in a final sample of 730 respondents. Missing observations appear to be missing at random, as no variables were significantly predictive of missing observations. The data collection protocols were reviewed and approved by the University of Akron Institutional Review Board.

Table 1 contains summary statistics for all variables included in our analysis. Nursing is a female-dominated occupation, and our sample, which is 92 percent female, largely reflects national gender demographics (U.S. Department of Labor 2013). Six percent of the sample is African American, five percent are another minority, and 89 percent of respondents are white. Forty-two percent of the sample is between the ages of 23 and 35, 29 percent is between the ages of 36 and 50, 29 percent of the sample is over the age of 50. About $40 \%$ had either a BSN or MSN (the reference category was an associate's degree).

\section{[Insert Table 1 about here]}

\section{Measures}

Employment outcomes. We examine three worker-related outcomes: burnout, physical well-being, and intent to turnover. We measure burnout using a scale of seven survey items adapted from Erickson and Ritter (2001). Sample survey items include "I feel emotionally drained," "I feel used up at the end of the day," "I dread getting up in the morning and having to 
face another work day," and "My work really puts a lot of strain on me" $(\alpha=.93)$. Respondents were asked to indicate how often they experienced the descriptions in the survey items: (0) never felt this way while at work (1) one or two times (2) about once a week, (3) a few times a week, (4) about once a week, (5) I felt this way every day.

We measure physical well-being using a checklist of eight physical symptoms, including headaches, stomachache/pain, chest or heart pain, coughing/sore throat, faintness or dizziness, stiff/sore muscles, shortness of breath, and runny or congested nose (adapted from Emmons 1991). Respondents were asked to indicate how often they experienced the physical symptoms described in the survey items: (1) rarely or never (2) a few times per year, (3) monthly, (4) weekly, (5) daily $(\alpha=.77)$.

Two survey items are used to measure intent to turnover, or intent to leave one's current employer: "I intend to leave [name of health system] in the next 12 months," and "I intend to remain with [name of health system] for a long time (reverse coded)." Response categories are strongly disagree (1), disagree (2), agree (3), and strongly agree (4).

Source of motivation. We measure three types of motivation: prosocial, intrinsic, and extrinsic motivation. Our measure of motivation type was adapted from survey items developed by Grant (2008a). The response categories for all survey items related to motivation source are "Not at all," "A little bit," "A moderate amount," or "A great deal." The two items for prosocial motivation are "Because I want to help others through my work," and "Because it is important to me to do good for others through my work $(\alpha=.87)$." Prosocial motivation is included as a binary variable in our models, where high prosocial motivation indicates that the individual answered "A great deal" in response to both statements above (1), and moderate prosocial motivation reflects anything less than complete agreement with both statements (0). Prosocial motivation is 
included as a binary variable in the analysis because most respondents reported a very high level of prosocial motivation, resulting in a highly skewed distribution. We attempted several transformations of the variable to achieve a more normal distribution but were unsuccessful. In looking at the distribution of the data, we decided that there was a meaningful break between individuals that reported the highest level of prosocial motivation and those that reported anything less that complete agreement with statements related to prosocial motivation. Thus, we include two categories of workers: workers that have high prosocial motivation (83\%) and those with moderate prosocial motivation $(17 \%)$.

The distributions of intrinsic and extrinsic motivation were more normally distributed across respondents. The three items for intrinsic motivation are "Because I enjoy the work itself," "Because it's fun," and "Because I find the work engaging $(\alpha=.80)$." The three items for extrinsic motivation are "Because the money I receive enables me to have a certain lifestyle," "Because it helps me to fulfill my financial obligations," and "It provides me flexibility in managing my schedule" $(\alpha=$.79). Intrinsic and extrinsic motivations are included as continuous variables in the analysis.

Care dimensions. In addition to type of motivation, we control for how nurses view their job tasks in terms of providing care for patients, as an individual's motives for choosing a career pathway are linked to what he or she values in a job (Kalleberg, 1977; London, 1983). Nursing is considered to be "caring labor," but the tasks and responsibilities that individuals view as vital to the process of "caring" can vary. Today's nurses have a wide range of job tasks and responsibilities (which vary further by specialty and setting), and while some individuals may view the psychosocial and relational dimension of their job as central to caring, other nurses may 
hold a more technical orientation toward care and value having a high degree of clinical expertise (Apesoa-Varano, 2007; Cottingham, 2014; Lindsay, 2008).

We distinguish between two different orientations towards care: psychosocial orientation towards care and technical orientation towards care. We use 19 survey items adapted from the Caring Dimensions Inventory (CDI-35) developed by Watson, Deary, and Hoogbruin (2001). Participants were asked to respond to the following prompt: "To be a good nurse, to what extent do you feel/believe/think you should be engaged in the following activities?" Examples of items categorized as a technical orientation towards care include "Making a nursing record about a patient," "Being technically competent with a clinical procedure," and "Measuring the vital signs of a patient" $(\alpha=.81)$. Examples of items categorized as a psychosocial orientation towards care include, "Listening to a patient," "Getting to know the patient as a person," and "Being honest with a patient" $(\alpha=.87)$. The response categories for all items were "Not at all," "A little bit," "A moderate amount," or "A great deal."

Other control variables. Additional control variables included in the analysis include sex (male is the reference category), racelethnicity (Black, other minority race/ethnicity, or white as reference category), and age (26-35 years, 36-50 years, and 51+ years as reference category).

Finally, we include a measure of the respondent's perception of patient acuity in the setting in which they work to control for differences in the type of nursing care provided. Respondents answered the question, "What is the typical patient acuity on your unit?" We indicate if perception of patient acuity is high/very high (1) or low/medium (0). We include perceived patient acuity as a control variable because past research has shown that nurses who work in settings where patients have more acute needs are more likely to have a technical orientation towards care (Lea \& Watson, 1999; Wilkin \& Slevin, 2004). 


\section{Analyses}

In our analysis, we examine sources of motivation as predictors of a variety of worker outcomes, including intent to leave one's job, job burnout, and physical well-being. All analyses were run as ordinary least-squares regression models. Pearson and phi correlations as well as variance inflation factors (VIF) after each regression did not indicate problematic multicollinearity. All analyses were conducted in Stata 12.0.

\section{FINDINGS}

Regression analyses. Table 2 presents the results for the analyses of predictors of three worker outcomes: job burnout, physical symptoms, and intent leave one's current employer. Nurses who report high levels of prosocial motivation are more likely to report high levels of burnout at work $(0.26, \mathrm{p}<.01)$, supporting Hypothesis 1a. Nurses who report high levels of intrinsic motivation for their jobs are less likely to report high levels of burnout at work (-0.76, $\mathrm{p}<.001$ ) (Table 2, Model 1), which supports our Hypothesis 1b. We also found that nurses that reported extrinsic motivation were less likely to report high levels of burnout at work $(-0.27$, $\mathrm{p}<.001$ ), which is the opposite of our prediction in Hypothesis 1c. Care dimensions are not significantly related to burnout. Nurses below age 50 years of age are also more likely to report high levels of burnout as compared to their older counterparts $(0.29, \mathrm{p}<.05 ; 0.28, \mathrm{p}<.01)$.

Nurses who report high intrinsic motivation report fewer physical symptoms $(-0.21$, $\mathrm{p}<.001$ ) (Table 2, Model 2), which is consistent with Hypotheses 2b. We also found that nurses reporting high extrinsic motivation report fewer physical symptoms $(-0.14, \mathrm{p}<.001)$, which is the opposite of our prediction in Hypothesis 2c. Prosocial motivation is not significantly related to physical symptoms. Care dimensions are not significantly related to physical symptoms. Females 
report higher physical symptoms $(0.21, \mathrm{p}<.05)$ as do nurses under age $50(0.26, \mathrm{p}<.001 ; 0.20$, $\mathrm{p}<.01)$.

Finally, workers with high levels of intrinsic and extrinsic motivation to pursue care work are less likely to say that they intend to leave their current employer $(-0.28, \mathrm{p}<.001 ;-0.17$, $\mathrm{p}<.001$ ), supporting Hypotheses $3 \mathrm{~b}$ and $3 \mathrm{c}$, while prosocial motivation is not significantly related to intent to turnover (Table 2, Model 3). Neither technical nor psychosocial caring dimensions are not significantly related to employment intentions. Younger nurses (ages 25-35) are more likely to say that they intend to leave their current employer $(0.21, \mathrm{p}<.01)$.

\section{[Insert Table 2 about here]}

Interactions between sources of motivation. Past research has shown that sources of motivation may interact to influence worker outcomes. For example, Grant (2008a) found that intrinsic motivation strengthens the relationship between prosocial motivation and persistence during the workday. He argued that when intrinsic motivation is high, employees feel that completing their tasks is beneficial to achieving their goals; thus, as these autonomously motivated workers are enjoying the process of working and value the outcome of helping others, these feelings lead to better employment outcomes. Conversely, when intrinsic motivation is low, workers do not enjoy their job tasks, but they put pressure on themselves to do the tasks in order to help others. Here, prosocial motivation is based in guilt and a sense of obligation, and workers may respond by "burning out" or intending to leave their job.

To test whether intrinsic motivation moderates the relationship between prosocial motivation and worker outcomes, as well as other moderated relationships between types of motivation, we tested models that included interaction terms for these relationships. However, 
none of the interaction terms were statistically significant in any of our models, so we did not include them in our final analyses shown in Table 2.

\section{DISCUSSION}

Grant's work on the benefits of prosocial motivation has recently received a lot of attention both in academic journals and the popular press, arguing that prosocial motivation benefits both workers and organizations by leading workers to go above and beyond the call of duty to persist in performing their work effectively and productively (Grant, 2008a; Grant, 2008b; Grant \& Sonnentag, 2010; Grant \& Berry, 2011). However, literature on care work and emotional labor have long warned of the hazards of investing one's self too heavily in helping others, particularly in caring occupations (e.g., Hochschild, 1983; Maslach, 2003; Nelson, 1999). In caring labor, a prosocial orientation grounded in the desire to help and promote the well-being of other people is assumed to be the "right" motivation for entering such occupations. The assumption is that other motivations may lead to an individual performing the work for the "wrong reason," which may result in the individual being less "caring" on the job and therefore less effective as a worker (Heyes, 2005; Nelson \& Folbre, 2006). Literature on burnout and physical well-being among care workers, though, suggests that very high prosocial motivation may be debilitating to the well-being of individuals (Maslach, 2003).

In the current study, we tested the relationships between different sources of motivation among nurses and a variety of nurse outcomes, including job burnout, negative physical symptoms, and intent to turnover. Would high prosocial motivation lead to better worker outcomes, as Grant would suggest? Or would high prosocial motivation be related to more negative worker outcomes, particularly burnout, as the care work literature would imply? Our study suggests that high prosocial motivation is related to higher levels of worker burnout; 
workers who report very high prosocial motivation also report higher levels of burnout at work as compared to workers with lower levels of prosocial motivation. Thus, our findings related to prosocial motivation are consistent with literature on care work and emotional labor (Barron \& West, 2007) and stand in contrast to Grant's work on prosocial motivation and self-determination theory (SDT).

At the same time, nurses who report high levels of intrinsic motivation for performing caring report significantly lower levels of burnout at work and fewer physical symptoms. Our findings are consistent with past research on self-determination theory, which has shown that high intrinsic motivation is always better for well-being as compared to low intrinsic motivation (Bono \& Judge, 2003; Deci \& Ryan, 2000; Sheldon \& Elliot, 1998; Sheldon \& Elliott, 1999). In addition, we were surprised to find that nurses that reported high extrinsic motivation, meaning that they were highly motivated by wages and other extrinsic rewards, also reported significantly lower levels of burnout and physical symptoms. These findings indicate that workers who pursue caring labor for reasons other than - or in addition to - prosocial motivations find caring labor to be less stressful, both emotionally and physically. It may be that nurses who are motivated by intrinsic or extrinsic rewards may be able to maintain greater emotional distance from patients, and this detachment may lead to lower burnout and stress on the body (Maslach et al., 2001). As argued earlier, nurses with high prosocial motivations may be at risk for identifying too closely with their patients and consequently may be less likely to develop a "healthy" estrangement from the interactional stresses of the job (Hochschild, 1983).

Workers with high intrinsic and extrinsic motivations for working in nursing are also significantly less likely to form turnover intentions. Gendered assumptions about caring labor suggest that workers who are highly motivated by helping others are more likely to stay in their 
jobs because of the "love" that they hold for patients (England, 2005). However, we did not find that prosocial motivation was significantly related to quit intentions, and, in fact, those with high intrinsic and extrinsic motivations are actually less likely to say that they intend to leave their current positions, perhaps because they feel less burnt out at work or are experiencing fewer negative physical symptoms. A recent study by Nesje (2015) found that prosocial motivations as a nursing student were predictive of job commitment three years later; however, the researcher limited their examinations to only prosocial motivations, which may bias the results. It also demonstrates that the prosocial bias in nursing is so strong that the author did not consider measuring intrinsic or extrinsic motives.

The differential impact of intrinsic and prosocial motivation on worker outcomes indicates that these are indeed separate and distinct sources of motivation within caring labor and should be considered in future research on motivation within nursing. As discussed above, some researchers have argued that there is little in the actual performance of care work that would be intrinsically rewarding for workers apart from the prosocial rewards of the occupation. Thus, the "love or money" debate around why individuals perform caring labor typically excludes intrinsic motivations or conflates intrinsic and prosocial motivations (England, Folbre, \& Leana, 2012). We found, however, that prosocial and intrinsic motivations operate differently in terms of worker outcomes. As we argue in the introduction, the occupation of nursing is becoming increasingly technical, which may be related to an increase in the intrinsic rewards of the job. An implication of our findings, then, is that the debate about the consequences of worker motivations in caring labor needs to be expanded beyond "love and money" to reflect the conditions and job responsibilities of caring labor today (Apesoa-Varano, 2007). 


\section{Limitations and Directions for Future Research}

A limitation of the study is that we are using cross-sectional data, which does not allow us to examine the causal direction between worker motivation and burnout, negative physical symptoms, and intent to turnover. As motivation has been shown to be a dynamic variable that fluctuates within-person over time (Benedetti et al., in press), it would be helpful to have a longitudinal perspective of the relationship between motivations for pursuing caring labor and worker outcomes. For example, it is possible that burnout and physical symptoms are experiences that can precede motivation and intention; thus, burnout and physical symptoms may be reasonable predictors of motivation and intention. As we do not have access to longitudinal data, we cannot test the causal direction in these relationships. However, the vast majority of theory and research on SDT places motivation as an antecedent of psychological need satisfaction and individual well-being (Deci \& Ryan, 2000; Gagne \& Deci, 2005).

Another limitation of the study is that we do not include a measure of worker performance. While the debate surrounding worker motivations in caring labor is implicated in performance at work, unfortunately we do not have any measures of nurse effectiveness or patient outcomes. Thus, an obvious extension of this study would be to look closely at the relationships between motivations, care dimensions, and performance at work. Our sample is also limited to nurses in one health system in the United States, and our understanding of these relationships would benefit from expanding our study to include a broader population of nurses and other care workers within distinct cultural settings.

As argued throughout this paper, there is a historic assumption within caring labor that the best workers are those that are highly motivated by helping others and a familial model of care. However, our study suggests that nurses who have high prosocial motivations may also be 
prone to burnout and other physical symptoms, and may also exhibit lower levels of attachment to the organization. Further, our research suggests that nurses who are intrinsically motivated (i.e., who find inherent enjoyment in their jobs tasks) and those who are motivated by extrinsic rewards (i.e., salary and benefits) have better outcomes for themselves and their organizations, including lower burnout, lower physical symptoms, and high job commitment. These findings have implications for the conceptualization of "good" caring labor as well as what constitutes a "good" orientation to care work within today's health care environment. As such, these results may help health care leaders to address questions such as: should we be concerned about the effect of higher wages on care workers? Will there be an influx of non-carers into the market, drawn in by the "wrong" motives? Fears about the motives of care workers may be related to the idea that marketization brings norms of self-interest and individualism that are incompatible with the familial ideal of care, or the development of authentic caring relationships. However, our findings suggest that motives beyond prosocial motivation are protective for the health of workers and may benefit organizations and patients as well. 


\section{REFERENCES}

Apesoa-Varano, E.C. (2007). Educated caring: The emergence of professional identity among nurses. Qualitative Sociology, 30, 249-274.

Attree, M. (2001). Patients' and relatives' experiences and perspectives of 'good' and 'not so good' quality care. Journal of Advanced Nursing, 33, 456-466.

Autor, D. (2010). The polarization of job opportunities in the US labor market: Implications for employment and earnings. Center for American Progress and the Hamilton Project.

Barron, D.N., \& West, E. (2007). The emotional costs of caring incurred by men and women in the British labour market. Social Science \& Medicine, 65, 2160-2171.

Basford, L., \& Slevin, O. (2003). Theory and practice of nursing: An integrated approach to caring practice. Cheltenham, UK: Nelson Thornes.

Batson, C.D., \& Powell, A.A. (2003). Altruism and prosocial behavior. Handbook of Psychology. Hoboken, NJ: Wiley.

Benedetti, A., Diefendorff , J., Gabriel, A., \& Chandler, M. (in press). The effects of intrinsic and extrinsic sources of motivation on well-being depend on time of day: The moderating effects of workday accumulation. Journal of Vocational Behavior.

Bono, J.E., \& Judge, T.A. (2003). Self-concordance at work: Toward understanding the motivational effects of transformational leadership. Academy of Management Journal, $46,554-571$.

Brotheridge, C., \& Grandey, A.A. (2002). Emotional labor and burnout: Comparing two perspectives of 'people work.' Journal of Vocational Behavior, 60,17-39.

Buerhaus, P., Staiger, D., \& Auerbach, D. (2009). The future of the nursing workforce in the United States: Data, trends and implications. Burlington, MA: Jones \& Bartlett Publishers. 
Cordes, C.L., \& Dougherty, T.W. (1993). A review and an integration of research on job burnout. Academy of Management Review, 18, 621-656.

Cotter, D.A., Hermsen, J.M., \& Vanneman, R. (2004). Gender inequality at work. New York: Russell Sage Foundation.

Cottingham, M.D. (2014). Recruiting men, constructing manhood: How health care organizations mobilize masculinities as nursing recruitment strategy. Gender \& Society, 28, 133-156.

Deci, E.L., \& Ryan, R.M. (2000). The "what" and "why” of goal pursuits: Human needs and the self-determination of behavior. Psychological Inquiry, 11, 227-268.

Dodson, L., \& Zincavage, R.M. (2007). It's like a family: Caring labor, exploitation, and race in nursing homes. Gender \& Society, 21, 905-928.

Duffy, M. (2005). Reproducing labor inequalities. Gender \& Society, 19, 66-82.

Emmons, R.A. (1991). Personal strivings, daily life events, and psychological and physical wellbeing. Journal of Personality, 59, 453-472.

England, P. (2005). Emerging theories of care work. Annual Review of Sociology, 31, 381-399.

England, P., Budig, M., \& Folbre, N. (2002). Wages of virtue: The relative pay of care work. Social Problems, 49, 455-473.

England, P., Folbre, N., \& Leana, C. (2012). Motivating Care. In N. Folbre (Ed), For love and money: Care provision in the United States (p.21-39). New York: Russell Sage Foundation.

Erickson, R.J., \& Ritter, C. (2001). Emotional labor, burnout, and inauthenticity: Does gender matter? Social Psychology Quarterly, 64, 146-163.

Folbre, N., \& Nelson, J.A. (2000). For love or money—or both? The Journal of Economic Perspectives, 14, 123-140. 
Gagné, M., \& Deci, E.L. (2005). Self-determination theory and work motivation. Journal of Organizational Behavior, 26, 331-362.

Gauchat, G., Kelly, M., \& Wallace, M. (2012). Occupational gender segregation, globalization, and gender earnings inequality in us metropolitan areas. Gender \& Society, 26, 718-747.

Gendolla, G., Abele, A., Andrei, A., Spurk, D., \& Richter, M. (2005). Negative mood, selffocused attention, and the experience of physical symptoms: The joint impact hypothesis. Emotion, 5, 131-144.

Gerstel, N. (2000). The third shift: Gender and care work outside the home. Qualitative Sociology, 23, 467-483.

Grant, A.M. (2008a). Does intrinsic motivation fuel the prosocial fire? Motivational synergy in predicting persistence, performance, and productivity. Journal of Applied Psychology, 93, 48-58.

—. (2008b). Employees without a Cause: The Motivational Effects of Prosocial Impact in Public Service. International Public Management Journal, 11, 48-66. . (2013). Give and take: Why helping others drives our success. New York: Penguin Books.

Grant, A.M., \& Berry, J.W. (2011). The necessity of others is the mother of invention: Intrinsic and prosocial motivations, perspective taking, and creativity. Academy of Management Journal, 54, 73-96.

Grant, A.M., \& Sonnentag, S. (2010). Doing Good Buffers Against Feeling Bad: Prosocial Impact Compensates for Negative Task and Self-Evaluations. Organizational Behavior and Human Decision Processes, 111, 13-22. 
Hayes, L., O’Brien-Pallas, L., Duffield, C., Shamian, J., Buchan, J., Hughes, F., Spence, H.K., North, N., \& Stone, P. (2006). Nurse turnover: A literature review. International Journal of Nursing Studies, 43, 237-263.

Herzberg, F., Mausner, B., \& Snyderman, B.B. (1959). Motivation to work. New Brunswick, NJ: Transaction Publishers.

Heyes, A. (2005). The Economics of Vocation Or Why is a Badly Paid Nurse a Good Nurse? Journal of Health Economics, 24, 561-570.

Himmelweit, S. (1999). Caring Labor. The Annals of the American Academy of Political and Social Science, 561, 27-38.

Hochschild, A. (1983). The managed heart: Commercialization of human feeling. Berkeley, CA: University of California Press.

Houkes, I., Janssen, P.P.M., de Jonge, J., \& Bakker, A.B. (2003). Specific determinants of intrinsic work motivation, emotional exhaustion and turnover intention: A multisample longitudinal study. Journal of Occupational and Organizational Psychology, 76, 427-450.

Jacoby, D. (2006). Caring about caring labor: An introduction. Politics \& Society, 34, 5-9.

Janssen, P.P.M, de Jonge, J., \& Bakker, A.B. (1999). Specific determinants of intrinsic work motivation, burnout and turnover intentions: A study among nurses. Journal of Advanced Nursing, 29, 1360-1369.

Judd, D., \& Sitzman, K. (2013). A history of American nursing: Trends and eras. Burlinton, MA: Jones and Bartlett Learning.

Kalleberg, A. (2011). Good jobs, bad jobs: The rise of polarized and precarious employment systems in the United States, 1970s-2000s. New York: Russell Sage Foundation, American Sociological Association Rose Series in Sociology. 
Kalleberg, A. (1977). Work values and job rewards: A theory of job satisfaction. American Sociological Review, 42, 124-143.

Lang, J., Ochsmann, E., \& Kraus, T., \& Lang, J. (2012). Psychosocial work stressors as antecedents of musculoskeletal problems: A systematic review and meta-analysis of stability-adjusted longitudinal studies. Social Science \& Medicine, 75, 1163-1174.

Larrabee, J., Janney, M., Ostrow, C.L., Withrow, M.L., Hobbs, G., \& Burant, C. (2003). Predicting registered nurse job satisfaction and intent to leave. Journal of Nursing Administration, 33, 271-283.

Lea, A., \& Watson, R. (1999). Perceptions of caring among nurses: The relationship to clinical area. Journal of Clinical Nursing, 8, 617-618.

Lindsay, S. (2008). The care-tech link: an examination of gender, care and technical work in healthcare labour. Gender, Work \& Organization, 15, 333-351.

London, M. (1983). Toward a theory of career motivation. Academy of Management Review, 8, 620-630.

Lucero, R.J., Lake, E.T., \& Aiken, L.H. (2010). Nursing care quality and adverse events in us hospitals. Journal of Clinical Nursing, 19, 2185-2195.

Maslach, C. (2003). Burnout: The Cost of Caring. Los Altos, CA: Malor Books.

Maslach, C., Schaufeli, W.B., \& Leiter, W.P. (2001). Job burnout. Annual Review of Psychology, 52, 397-422.

Meagher, G. (2006). What can we expect from paid carers? Politics \& Society, 34, 33-54.

Nelson, J.A. (1999). Of markets and martyrs: Is it ok to pay well for care? Feminist Economics, 5, 43-59. 
Nesje, K. (2015). Nursing students' prosocial motivation: Does it predict professional commitment and involvement in the job? Journal of Advanced Nursing, 71, 115-125.

Pearlin, Leanard. (1989). The sociological study of stress. Journal of Health and Social Behavior, 30, 241-256.

Pullen, A., \& Simpson, R. (2009). Managing difference in feminized work: Men, otherness and social practice. Human Relations, 62, 561-587.

Ryan, R.M., \& Deci, E.L. (2000). Self-determination theory and the facilitation of intrinsic motivation, social development, and well-being. American Psychologist, 55, 68-78.

Schaubroeck, J., \& Jones, J.R. (2000). Antecedents of workplace emotional labor dimensions and their effects on physical symptoms. Journal of Organizational Behavior, 21, 163-183.

Sheldon, K. M., \& Elliot, A. J. (1998). Not all personal goals are personal: Comparing autonomous and controlled reasons for goals as predictors of effort and attainment. Personality and Social Psychology Bulletin, 24, 546-557.

Sheldon, K. M., \& Elliot, A. J. (1999). Goal striving, need satisfaction, and longitudinal wellbeing: The Self-Concordance Model. Journal of Personality and Social Psychology, 76, 482-497.

Stone, D. (2000). Caring by the Book. Care Work: Gender, Labor and the Welfare State, edited by Madonna Harrington Meyer. New York: Routledge.

Thistle, S. (2006). From marriage to the market: The transformation of women's lives and work. Berkeley, CA: University of California Press.

Tourangeau, A.E., Cummings, G., Cranley, L.A., Ferron, E.M., \& Harvey, S. (2010). Determinants of hospital nurse intention to remain employed: Broadening our understanding. Journal of Advanced Nursing, 66, 22-32. 
U.S. Department of Labor, Bureau of Labor Statistics. (2012). Employment by major occupational group. Retrieved from http://www.bls.gov/emp/ep_table_101.htm

U.S. Department of Labor, Bureau of Labor Statistics. (2013). Male nurses becoming more commonplace, Census Bureau Reports. Retrieved from http://www.census.gov/newsroom/releases/archives/employment_occupations/cb13$\underline{32 . h t m l}$

Watson, R., \& Hoogbruin, A.L. (2001). A 35-item version of the caring dimensions inventory (cdi-35): Multivariate analysis and application to a longitudinal study involving student nurses. International Journal of Nursing Studies, 38, 511-521.

Wilkin, K., \& Slevin, E. (2004). The meaning of caring to nurses: An investigation into the nature of caring work in an intensive care unit. Journal of Clinical Nursing, 13, 50-59. 
Tables (NO AUTHOR DETAILS)

Table 1. Descriptive statistics and correlation matrix.

\begin{tabular}{|c|c|c|c|c|c|c|c|c|c|c|c|c|c|c|c|c|}
\hline & Variable & Mean & (SD) & (1) & (2) & (3) & (4) & (5) & (6) & (7) & $(8)$ & (9) & $(10)$ & (11) & $(12)$ & (13) \\
\hline (1) & Intent to leave & 1.81 & $(0.73)$ & & & & & & & & & & & & & \\
\hline (2) & Burnout & 3.27 & $(1.05)$ & 0.32 & & & & & & & & & & & & \\
\hline (3) & Physical symptoms & 2.18 & $(0.65)$ & 0.10 & 0.48 & & & & & & & & & & & \\
\hline (4) & High prosocial motivation & 0.83 & $(0.37)$ & $-0.09^{+}$ & $-0.10^{+}$ & $-0.09^{+}$ & & & & & & & & & & \\
\hline (5) & Intrinsic motivation & 3.13 & $(0.62)$ & -0.30 & -0.49 & -0.25 & $0.36^{+}$ & & & & & & & & & \\
\hline (6) & Extrinsic motivation & 2.84 & $(0.69)$ & -0.24 & -0.32 & -0.21 & $0.11^{+}$ & 0.32 & & & & & & & & \\
\hline (7) & Technical care & 3.27 & $(0.47)$ & -0.11 & -0.14 & -0.06 & $0.19^{+}$ & 0.25 & 0.10 & & & & & & & \\
\hline (8) & Psychosocial care & 3.53 & $(0.45)$ & -0.04 & -0.09 & -0.04 & $0.14^{+}$ & 0.16 & 0.08 & 0.49 & & & & & & \\
\hline (9) & Female & 0.92 & $(0.28)$ & $-0.01^{+}$ & $0.04^{+}$ & $0.08^{+}$ & $0.03^{++}$ & $0.01^{+}$ & $0.03^{+}$ & $0.04^{+}$ & $0.10^{+}$ & & & & & \\
\hline (10) & Black & 0.06 & $(0.23)$ & $0.03^{+}$ & $-0.05^{+}$ & $-0.04^{+}$ & $0.03^{++}$ & $0.05^{+}$ & $-0.05^{+}$ & $0.09^{+}$ & $0.03^{+}$ & $0.03^{++}$ & & & & \\
\hline (11) & Other minority & 0.05 & $(0.22)$ & $0.05^{+}$ & $0.01^{+}$ & $-0.03^{+}$ & $0.03^{++}$ & $0.00^{+}$ & $0.01^{+}$ & $0.01^{+}$ & $-0.06^{+}$ & $0.00^{++}$ & $-0.06^{++}$ & & & \\
\hline (12) & Age 23-35 & 0.42 & $(0.49)$ & $0.17^{+}$ & $0.13^{+}$ & $0.16^{+}$ & $-0.02^{++}$ & $-0.09^{+}$ & $-0.01^{+}$ & $-0.12^{+}$ & $0.01^{+}$ & $0.09^{++}$ & $-0.03^{++}$ & $0.00^{++}$ & & \\
\hline (13) & Age $36-50$ & 0.29 & $(0.45)$ & $-0.08^{+}$ & $0.01^{+}$ & $0.00^{+}$ & $0.01^{++}$ & $0.04^{+}$ & $-0.01^{+}$ & $0.04^{+}$ & $0.04^{+}$ & $-0.13^{++}$ & $0.04^{++}$ & $0.05^{++}$ & $-0.56^{+}$ & \\
\hline (14) & High patient acuity & 0.57 & $(0.50)$ & $0.03^{+}$ & $0.17^{+}$ & $0.08^{+}$ & $-0.02^{++}$ & $-0.04^{+}$ & $-0.03^{+}$ & $0.09^{+}$ & $-0.02^{+}$ & $0.01^{++}$ & $-0.02^{++}$ & $0.00^{++}$ & $0.19^{+}$ & $-.07^{+}$ \\
\hline
\end{tabular}

Source: CARMA dataset

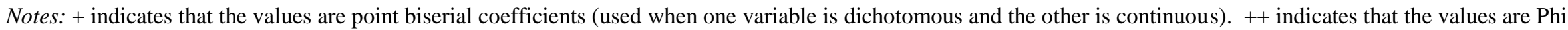
coefficients (used when both variables are dichotomous). All other values are Person's r coefficients. 
Table 2. Results of regression analyses of motivation source on worker outcomes.

\begin{tabular}{|c|c|c|c|c|c|c|}
\hline & \multirow{2}{*}{\multicolumn{2}{|c|}{$\begin{array}{l}\text { Model } 1 \\
\text { Burnout }\end{array}$}} & \multicolumn{2}{|c|}{ Model 2} & \multicolumn{2}{|c|}{ Model 3} \\
\hline & & & Physical & ymptoms & Intent & turnover \\
\hline \multicolumn{7}{|l|}{ Motivation type } \\
\hline \multirow[t]{2}{*}{ High prosocial motivation } & $0.25 *$ & $0.26 * *$ & 0.00 & 0.00 & 0.05 & 0.02 \\
\hline & $(0.09)$ & $(0.09)$ & $(0.06)$ & $(0.07)$ & $(0.07)$ & $(0.07)$ \\
\hline \multirow[t]{2}{*}{ Intrinsic motivation } & $-0.78 * * *$ & $-0.76 * * *$ & $-0.22 * * *$ & $-0.21 * * *$ & $-0.29 * * *$ & $-0.28 * * *$ \\
\hline & $(0.06)$ & $(0.06)$ & $(0.04)$ & $(0.04)$ & $(0.05)$ & $(0.05)$ \\
\hline \multirow[t]{2}{*}{ Extrinsic motivation } & $-0.27 * * *$ & $-0.27 * * *$ & $-0.13 * * *$ & $-0.14 * * *$ & $-0.17 * * *$ & $-0.17 * * *$ \\
\hline & & $(0.05)$ & $(0.04)$ & $(0.04)$ & (0.04) & $(0.04)$ \\
\hline \multicolumn{7}{|l|}{ Care dimensions } \\
\hline \multirow[t]{2}{*}{ Technical orientation } & & -0.04 & & 0.04 & & -0.06 \\
\hline & & $(0.08)$ & & $(0.06)$ & & $(0.07)$ \\
\hline \multirow[t]{2}{*}{ Psychosocial orientation } & & -0.06 & & -0.04 & & 0.04 \\
\hline & & $(0.09)$ & & $(0.06)$ & & $(0.07)$ \\
\hline \multicolumn{7}{|l|}{ Personal demographics } \\
\hline \multirow[t]{2}{*}{ Female } & & 0.20 & & $0.21 *$ & & -0.05 \\
\hline & & $(0.12)$ & & $(0.08)$ & & $(0.09)$ \\
\hline White & & Reference & & Reference & & Reference \\
\hline \multirow[t]{2}{*}{ Black } & & -0.20 & & -0.12 & & 0.11 \\
\hline & & $(0.14)$ & & $(0.10)$ & & $(0.11)$ \\
\hline \multirow[t]{2}{*}{ Other minority } & & -0.01 & & -0.10 & & 0.21 \\
\hline & & $(0.15)$ & & $(0.11)$ & & $(0.12)$ \\
\hline \multirow[t]{2}{*}{ Age $23-35$} & & $0.25 * *$ & & $0.26 * * *$ & & $0.21 * *$ \\
\hline & & $(0.08)$ & & $(0.06)$ & & $(0.06)$ \\
\hline \multirow[t]{2}{*}{ Age $36-50$} & & $0.25 * *$ & & $0.20 * *$ & & -0.01 \\
\hline & & $(0.09)$ & & $(0.06)$ & & $(0.07)$ \\
\hline Age 51+ & & Reference & & Reference & & Reference \\
\hline \multicolumn{7}{|l|}{ Unit working conditions } \\
\hline \multirow[t]{2}{*}{ High patient acuity } & & $0.28 * * *$ & & 0.05 & & -0.01 \\
\hline & & $(0.07)$ & & $(0.05)$ & & $(0.05)$ \\
\hline \multirow[t]{2}{*}{ Constant } & & $6.03 * * *$ & & $2.88 * * *$ & & $3.11 * * *$ \\
\hline & & $(0.33)$ & & $(0.23)$ & & $(0.26)$ \\
\hline R-squared & 0.27 & 0.31 & 0.08 & 0.12 & 0.11 & 0.14 \\
\hline Adjusted R-squared & 0.27 & 0.30 & 0.08 & 0.11 & 0.11 & 0.13 \\
\hline
\end{tabular}

Source: CARMA dataset

Standard errors in parentheses

$* \mathrm{p}<.05, * * \mathrm{p}<.01, * * * \mathrm{p}<.001$ 